\title{
Influence of perceived organisational factors on job burnout: survey of community mental health staff
}

Antonio Lasalvia, Chiara Bonetto, Mariaelena Bertani, Sarah Bissoli, Doriana Cristofalo, Giovanna Marrella, Enrico Ceccato, Carla Cremonese, Moreno De Rossi, Lorenza Lazzarotto, Vanna Marangon, Idana Morandin, Maria Zucchetto, Michele Tansella and Mirella Ruggeri on behalf of the PICOS-Veneto Group

\section{Background}

Staff burnout is a critical issue for mental healthcare delivery, as it can lead to decreased work performance and, ultimately, to poorer treatment outcomes.

\section{Aims \\ To explore the relative weight of job-related characteristics and perceived organisational factors in predicting burnout in staff working in community-based psychiatric services. \\ Method \\ A representative sample of 2000 mental health staff working in the Veneto region, Italy, participated. Burnout and perceived organisational factors were assessed by using the Organizational Checkup Survey.}

\section{Results}

Overall, high levels of job distress affected nearly two-thirds of the psychiatric staff and one in five staff members suffered from burnout. Psychiatrists and social workers reported the highest levels of burnout, and support workers and psychologists, the lowest. Burnout was mostly predicted by a higher frequency of face-to-face interaction with users, longer tenure in mental healthcare, weak work group cohesion and perceived unfairness.

\section{Conclusions}

Improving the workplace atmosphere within psychiatric services should be one of the most important targets in staff burnout prevention strategies. The potential benefits of such programmes may, in turn, have a favourable impact on patient outcomes.

\section{Declaration of interest}

None.
Professionals caring for people with long-term and serious illnesses are frequently exposed to distressing emotional situations and profound suffering, which can lead to burnout. ${ }^{1}$ Indeed, mental health staff represent one of the categories of health workers at highest risk of burnout, ${ }^{2,3}$ and burnout is a critical issue for mental healthcare delivery, as it can lead to the decreased effectiveness of the workforce and, ultimately, poorer treatment outcomes. ${ }^{4}$ Moreover, mental health services throughout Europe are currently facing severe financial shortages and consequent shortfalls in the number of sector-employed professionals. The situation is particularly pressing in European countries with a public national health service, such as the $\mathrm{UK}^{5}$ and Italy. ${ }^{6}$ In this context, workers' feelings of job disaffection and burnout can play a key role in further reducing the mental health service workforce.

Historically, burnout has been considered more a personal problem than an organisational one. ${ }^{7}$ Studies exploring determinants of burnout in mental health settings generally focus on individual sociodemographic factors, ${ }^{8-10}$ individual occupational characteristics, ${ }^{11-14}$ or on predisposing personality traits. ${ }^{15,16}$ Yet, recent research has expanded the theoretical burnout framework to include perceived organisational sources of stress. Maslach \& Leiter $^{7}$ proposed that burnout develops as the result of mismatches between professionals and their job contexts in several areas of working life. Specifically, mismatch occurs when the process of establishing a psychological 'contract' with one's job leaves critical issues unresolved, or when working relationships change in such a way as to feel unacceptable to the worker. Leiter \& Maslach ${ }^{17}$ accordingly proposed the 'mediation model', which postulates that the greater the worker-job mismatch, the greater the likelihood of burnout. The mediation model offers a promising approach for research and applied intervention, as it focuses upon the relationship of burnout to sources within the work context. ${ }^{18}$ Burnout is viewed from this perspective as an individual syndrome mediated in the work context, where perceived organisational factors have greater influence than personal factors. ${ }^{19-21}$ To date, however, no research in psychiatric settings has specifically focused on perceived occupational contexts by adopting the framework of the mediation model. ${ }^{17}$

Furthermore, most studies conducted in mental health settings generally examined one or two professional categories at a time (e.g. psychiatrists and/or social workers, nurses and/or occupational therapists), ${ }^{9-11,22-24}$ with only a few concurrently considering the wide range of mental health occupational profiles. $^{8,12,25}$

The present study surveyed a large, representative sample of Italian mental health staff. Its aims were to estimate and compare the prevalence of burnout among different occupational profiles, and to explore burnout predictors by considering both individual job-related characteristics and perceived organisational factors. Specifically, we hypothesised that: burnout among Italian mental health staff represents a serious concern, as it affects a considerable proportion of service staff; burnout differentially affects various psychiatric sector professional categories; and perceived organisational factors play a key role in predicting burnout.

\section{Method}

\section{Design}

The present study was a cross-sectional survey conducted in the broader context of the Psychosis Incident Cohort Outcome Study (PICOS) - a multisite collaborative research study assessing the 
outcome of individuals with first-episode psychosis attending community mental health services located in the Veneto region, Italy. The PICOS aims to develop a comprehensive model for predicting the outcome of first-episode psychosis by integrating genetic, magnetic resonance imaging and psychosocial factors. Of the putative predictors considered, contextual factors - i.e. the participating services' structural characteristics, the emotional atmosphere of the therapeutic milieu and the degree of worker burnout - are expected to play a crucial role in individuals' outcomes. $^{26-28}$

\section{The context of care}

Psychiatric care in Italy is delivered by the national health service through the departments of mental health. Each department of mental health is responsible for a geographically defined area, operates as a multidisciplinary team, deals with the full array of mental health needs of the local adult population and typically provides a wide range of comprehensive and integrated programmes, including in-patient, day care, rehabilitation, outpatient care, home visits, a 24-hour emergency service and residential facilities for long-term patients. ${ }^{6}$

\section{Participants}

All mental health staff employed in the PICOS catchment areas (approximately 3.7 million inhabitants) were eligible for the survey, which examined a wide range of job categories, such as psychiatrists, clinical psychologists, resident psychiatrists, hospital and community psychiatric nurses, occupational therapists, social workers, healthcare support workers, and secretarial staff. ${ }^{29}$ The data were collected from January to March 2005. Twenty-two of the 28 collaborating PICOS sites $(78.5 \%)$ agreed to participate and provided a list of their mental health staff. The surveyed sample is representative of mental health staff working in the public psychiatric sector in the Veneto region, since participants did not differ from non-participants in terms of sociodemographic characteristics and occupational profile and the participating sites did not differ from non-participating ones in terms of structural data (e.g. number of psychiatric in-patient beds per 10000 inhabitants, non-hospital residential facility beds per 10000 inhabitants) or location within the broader study catchment area (urban $v$. rural, deprived $v$. affluent) ( $t$-test, $P>0.05$ ) (data available from the authors).

\section{Measures}

Information was obtained by using the Italian version of the Organizational Checkup Survey (OCS), ${ }^{30,31}$ a comprehensive package comprising the following four schedules.

\section{Maslach Burnout Inventory-General Survey}

The Maslach Burnout Inventory-General Survey (MBI-GS) ${ }^{32}$ is a modified version of the original $\mathrm{MBI},{ }^{33}$ which consists of 16 items constituting three subscales. Emotional exhaustion (5 items) covers the experience of both emotional and physical fatigue; cynicism (5 items) reflects indifference, detached attitude towards work and active disengagement from work; professional efficacy ( 6 items) consists of feelings of competence, successful achievement and accomplishment in one's work, which diminish when burnout is developing. All MBI-GS items are scored on a seven-point rating scale ranging from zero (never) to six (always).

Individuals with burnout were defined based on the Dutch cut-off scores, ${ }^{34}$ the only published validated European cut-off scores available in the literature, i.e. exhaustion $>2.20$ and either cynicism $>2.00$ or efficacy $<3.66$. Preliminary analyses provided evidence that the Dutch cut-off scores also apply to the Italian sample (details on the procedure and data available from the authors).

\section{Areas of Worklife Scale}

The Areas of Worklife Scale (AWS) ${ }^{18}$ is a self-report survey assessing six working life domains: workload (six items), which examines the amount of work to be done in a given time; control (three items) refers to the opportunity to make choices and decisions, to solve problems and to contribute to the fulfilment of responsibilities; reward (four items) relates to (both financial and social) recognition for contributions on the job; community (five items) describes the quality of the organisation's social environment; fairness (six items) relates to the perceived extent to which the organisation has consistent and equitable rules for everyone working there; values (five items) refers to the degree of correspondence between employees' personal and professional values and the organisation's principles and practices. Items are scored on a five-point Likert scale ranging from one ('strongly disagree') to five ('strongly agree').

\section{Evaluation of Changes}

The Evaluation of Changes is a self-rated scale assessing perceived changes in the organisation over the previous year; it consists of ten items scored on a five-point Likert scale ranging from one ('strongly negative change') to five ('strongly positive change').

\section{Management Areas}

This is a self-rated scale composed of three dimensions: leadership (six items); skills development (four items); and work-group cohesion (three items). Each item is scored on a five-point Likert scale ranging from one ('strongly disagree') to five ('strongly agree').

\section{Statistical analyses}

The chi-squared test was used to assess associations between categorical variables. Analysis of variance (ANOVA) was used to compare mean scores among independent groups. All tests were two-tailed at a significance level of 0.01 .

Generalized linear latent and mixed models (GLLAMMs) ${ }^{35}$ were used to explore predictors for the MBI-GS dimensions (exhaustion, cynicism, efficacy); burnout dimensions, one at a time, were modelled by linear regression equations, with different possible intercepts for different study sites. A first set of models was fitted with gender, years of mental health sector employment, type of labour contract, degree of face-to-face interaction with users and type of professional category each being entered as the independent variable (univariate models). A second set of models was estimated by entering all these variables, plus the perceived organisational factors (i.e. the six working life areas, perceived changes, and the three management areas) (multivariate models). The GLLAMMs considered the two-level hierarchical structure generated by the study design, i.e. individuals (level one) nested within study sites (level two). This structure generates a correlation pattern among the measures, which has to be taken into consideration to obtain reliable estimates of the regression coefficients. The GLLAMMs comprise both a fixed and a random part: the fixed part, by estimating regression coefficients, shows which characteristics affect burnout; the random part identifies the proportion of total variance explained by differences between study sites. Moreover, in order to check for the 'real' effect of 
study site, a sensitivity analysis was performed that did not use the cluster structure, i.e. the models were re-run with the same set of predictors without considering the constraint of study site (the effect of study site, however, was not significant (data available from the authors) and was therefore omitted from the final models). The same strategy was used for the binary dependent variable 'to be in burnout'.

The analyses were performed using SPSS 14.0 and Stata 8.0 ('gllamm' command) for Windows.

\section{Results}

\section{Participant characteristics}

A total of 2017 mental health staff employed in the 22 participating sites were asked to take part in the survey by completing the OCS; 1585 questionnaires were returned (78.6\%); the maximum number of questionnaires reporting information was 1499 , with 1328 questionnaires fully completed. The percentage of valid questionnaires per site ranged from $38.7 \%$ to $99.0 \%$ (chi-squared test, $P<0.01$ ). Online Table DS1 provides an overall view of the respondent sample's sociodemographic and job characteristics.

The majority of the participants were women $(64.8 \%)$, aged $36-65$ years $(67.8 \%)$, had completed secondary school $(40.4 \%)$, and nearly $61 \%$ had been employed in the mental health sector for at least 6 years. Most of the participants were permanently employed (79.1\%), full time (89.9\%), and most (88.0\%) had daily face-to-face interaction with service users. The most numerous job category groups were: psychiatric nurses $(42.2 \%)$, support workers $(22.9 \%)$ and psychiatrists (10.5\%). The study sites significantly differed for all the occupational and sociodemographic characteristics (except for gender), reflecting a wide heterogeneity in participating site composition (chi-square test, $P<0.001$ ).

\section{Participant burnout levels}

Table 1 shows the sample's three MBI-GS subscale score means. As compared with the Italian MBI-GS norms, ${ }^{31}$ our sample's standardised $t$-scores showed average burnout levels ( $t$-score range: 46-55) for all three subscales.

More than one-third of respondents reported high distress levels for exhaustion and a quarter of the sample reported high cynicism and low efficacy levels (Table 2). Analysis of variance and chi-squared tests revealed significant across-site exhaustion and cynicism differences $(P<0.001)$, but no differences for efficacy. The professional categories reporting the most severe exhaustion were social workers and psychiatrists $(50.0 \%$ and $37.6 \%$, respectively); the highest levels of severe cynicism were found among psychiatrists and mental health nurses $(23.0 \%$ and $21.0 \%$ respectively), and the lowest reported efficacy levels were observed among social workers and nurses $(34.2 \%$ and $24.0 \%$, respectively).

Table 2 also shows the proportion of respondents experiencing severe burnout. Indeed, nearly one-fifth of the overall sample showed signs of severe burnout. Significant across-site differences were found in the number of participants experiencing severe burnout levels (chi-squared test, $P<0.001$ ). Social workers represented the professional category with the highest burnout rates $(30.8 \%)$, the lowest was for psychologists $(12.0 \%)$.

\section{AWS, Evaluation of Changes, and Management Areas}

Mean scores for the six areas of the AWS, the ten items of the Evaluation of Changes scale, and the three dimensions of the Management Areas scale were compared across sites: ANOVA $(P<0.001)$ yielded significant differences for all the subscales,
Table 1 Mean scores for the three subscales of the Maslach Burnout Inventory-General Survey (MBI-GS)

\begin{tabular}{|lcc|} 
& \multicolumn{2}{c}{ MBI-GS, scores } \\
\cline { 2 - 3 } Subscale & Mean (s.d.) & Median (range) \\
\hline Exhaustion & $1.96(1.25)$ & $1.80(0.00-6.00)$ \\
\hline Cynicism & $1.53(1.22)$ & $1.20(0.00-6.00)$ \\
\hline Efficacy & $4.32(1.06)$ & $4.50(0.00-6.00)$ \\
\hline
\end{tabular}

\begin{tabular}{|c|c|}
\hline & Participants above (or below) the cut-off \\
\hline \multicolumn{2}{|c|}{ MGI-GS subscale, $n$ (\%) } \\
\hline Exhaustion $^{a}$ & $483(33.6)$ \\
\hline Cynicism & $370(25.7)$ \\
\hline Efficacy $^{c}$ & $341(23.7)$ \\
\hline Burnout, $n(\%)^{d}$ & 281 (19.6) \\
\hline \multicolumn{2}{|c|}{$\begin{array}{l}\text { a. Cut-off }>2.20, n=1438 \text {. } \\
\text { b. Cut-off }>2.00, n=1439 \text {. } \\
\text { c. Cut-off }<3.66, n=1436 \text {. } \\
\text { d. Burnout: exhaustion }>2.20 \text { and either cynicism }>2.00 \text { or efficacy }<3.66, n=1436 \text {. }\end{array}$} \\
\hline
\end{tabular}

indicating, as expected, a high degree of across-site variability in perceived organisational factors. Means, standard deviations, and correlations tables for all OCS measures are available from the authors upon request.

\section{MBI-GS component predictors}

Table 3 shows the univariate regression analyses results, with distress levels used for the three MBI-GS subscales as dependent variables, and sociodemographic and job characteristics as independent factors.

Higher exhaustion levels were found in staff employed for more than 1 year in mental health (suggesting a 'dose-response' relation thereby, i.e. a direct relation between exhaustion levels and years of employment), in permanent staff, in staff with frequent face-to-face patient interaction, and in social workers and psychiatrists (using psychologists as the reference category). Higher cynicism levels were found in men, in staff with longer tenure in mental health, in permanent staff, in nurses and psychiatrists. Lower efficacy was found in permanent staff and employees with temporary and atypical contracts.

Table 3 also shows the univariate logistic regression analyses results with the dependent variable of being in burnout. Risk of burnout was significantly higher for staff employed for more than 6 years, employees involved in face-to-face interaction with patients, social workers and nurses. Conversely, cooperative society employees showed a lower burnout risk.

Table 4 reports the multivariate regression analyses results, with the three MBI-GS dimensions used as dependent variables, and sociodemographics, job-related characteristics and perceived organisational factors used as independent variables.

Most univariate associations lost their significance, and other significant predictors pertaining to working-life and management areas emerged, when the perceived organisational factors were entered all together into the models. Specifically, the main exhaustion predictor was workload (i.e. the higher workload, the higher exhaustion); other significant predictors were changes, reward, skills development and control, with the model 


\begin{tabular}{|c|c|c|c|c|}
\hline \multirow[b]{2}{*}{ Univariate models } & \multicolumn{3}{|c|}{ Linear models, regression coefficients (s.e.) } & \multirow{2}{*}{$\frac{\text { Logistic model, OR }(95 \% \mathrm{Cl})}{\text { Burnout }}$} \\
\hline & Exhaustion & Cynicism & Efficacy & \\
\hline \multicolumn{5}{|l|}{ Gender } \\
\hline $\begin{array}{l}\text { Male } \\
\text { Female }\end{array}$ & Ref & $\begin{array}{c}\text { Ref } \\
-0.15(0.07)^{*}\end{array}$ & Ref & Ref \\
\hline \multicolumn{5}{|l|}{ Years employed in mental health } \\
\hline$<1 \mathrm{yr}$ & Ref & Ref & Ref & Ref \\
\hline $1-5 \mathrm{yrs}$ & $0.28(0.13)^{*}$ & & & \\
\hline $6-12$ yrs & $0.42(0.14)^{* *}$ & $0.34(0.13)^{* *}$ & & $2.58 * *(1.23-5.40)$ \\
\hline $13-20 \mathrm{yrs}$ & $0.54(0.15)^{* *}$ & $0.39(0.15)^{* *}$ & & $3.04 * *(1.41-6.53)$ \\
\hline$>20 \mathrm{yrs}$ & $0.63(0.14)^{\star *}$ & $0.38(0.14)^{\star *}$ & & $3.02 * *(1.42-6.41)$ \\
\hline \multicolumn{5}{|l|}{ Labour contract } \\
\hline $\begin{array}{l}\text { Permanent } \\
\text { Fixed-term }\end{array}$ & Ref & Ref & Ref & Ref \\
\hline Self-employment & & $-0.54(0.22)^{\star *}$ & & \\
\hline $\begin{array}{l}\text { Cooperative society employment } \\
\text { Other employment }\end{array}$ & $-0.43(0.12)^{\star \star}$ & $-0.46(0.12)^{\star *}$ & $\begin{array}{r}0.23(0.10)^{*} \\
-0.35(0.16)^{*}\end{array}$ & $0.17^{* *}(0.07-0.43)$ \\
\hline \multicolumn{5}{|l|}{ Face-to-face interaction with users } \\
\hline $\begin{array}{l}\text { No } \\
\text { Yes }\end{array}$ & $\begin{array}{l}\text { Ref } \\
028(010) * *\end{array}$ & Ref & Ref & Ref \\
\hline \multicolumn{5}{|l|}{ Profession } \\
\hline Psychologists & Ref & Ref & Ref & Ref \\
\hline Nurses & & $0.51(0.14)^{* *}$ & & $2.14 *(1.04-4.40)$ \\
\hline Social workers & $0.43(0.22)^{*}$ & & & $3.23 *(1.29-8.07)$ \\
\hline \multicolumn{5}{|l|}{ Occupational therapists } \\
\hline Support workers & & & & \\
\hline$* P<0.05 ; * * P<0.01$. & & & & \\
\hline
\end{tabular}

Table 4 Levels of distress in the three subscales of the Maslach Burnout Inventory-General Survey and condition of burnout in the overall sample: multivariate linear and logistic models $(n=1420)$. Only significant coefficients are reported

\begin{tabular}{|c|c|c|c|c|}
\hline \multirow[b]{2}{*}{ Multivariate models } & \multicolumn{3}{|c|}{ Linear models, regression coefficients (s.e.) } & \multirow{2}{*}{$\frac{\text { Logistic model, OR }(95 \% \mathrm{Cl})}{\text { Burnout }}$} \\
\hline & Exhaustion & Cynicism & Exhaustion & \\
\hline \multicolumn{5}{|l|}{ Employed in mental health, years } \\
\hline$<1$ & Ref & Ref & Ref & Ref \\
\hline $1-5$ & & & & \\
\hline $6-12$ & & & & \\
\hline $13-20$ & & & & $3.24 *(1.03-10.23)$ \\
\hline$>20$ & & & & \\
\hline \multicolumn{5}{|l|}{ Labour contract } \\
\hline Permanent & Ref & Ref & Ref & Ref \\
\hline Fixed-term & & & & \\
\hline Self-employment & & & & \\
\hline Cooperative society employment & & & & $0.08^{*}(0.01-0.64)$ \\
\hline Other employment & $-0.59(0.29)^{*}$ & & & \\
\hline \multicolumn{5}{|l|}{ Face-to-face interaction with users } \\
\hline No & Ref & Ref & Ref & Ref \\
\hline Yes & & & & $4.81^{* *}(1.70-13.57)$ \\
\hline \multicolumn{5}{|l|}{ Perceived organisational factors } \\
\hline Workload $^{\mathrm{a}}$ & $1.08(0.07)^{\star *}$ & $0.28(0.07)^{* *}$ & & $0.23^{* *}(0.15-0.34)$ \\
\hline Control & $-0.15(0.07)^{*}$ & $-0.25(0.07)^{* *}$ & $0.55(0.06)^{* *}$ & $0.51 * *(0.34-0.76)$ \\
\hline Reward & $-0.22(0.06)^{* *}$ & $-0.35(0.06)^{* *}$ & $0.24(0.06)^{* *}$ & $0.39 * *(0.27-0.57)$ \\
\hline \multicolumn{5}{|l|}{ Community } \\
\hline Fairness & & $-0.29(0.09)^{\star *}$ & $0.28(0.08)^{* *}$ & $0.53^{* *}(0.33-0.84)$ \\
\hline \multicolumn{5}{|l|}{ Values } \\
\hline Changes & $-0.35(0.09)^{\star *}$ & $-0.39(0.09)^{\star *}$ & & $0.46 * *(0.26-0.79)$ \\
\hline \multicolumn{5}{|l|}{ Leadership } \\
\hline Skills development & $-0.18(0.07)^{* *}$ & $-0.22(0.07)^{* *}$ & & \\
\hline Work-group cohesion & & $-0.19(0.07)^{\star *}$ & $0.20(0.07)^{* *}$ & $0.65 *(0.43-0.99)$ \\
\hline$R^{2}$-adj, \% & 37.2 & 26.5 & 15.7 & $29.3^{\mathrm{b}}$ \\
\hline $\begin{array}{l}\text { a. High values indicated low workload. } \\
\text { b. Cox \& Snell } R^{2} \text {. } \\
* P<0.05 ; * *<0.01 \text {. }\end{array}$ & & & & \\
\hline
\end{tabular}


accounting for $37 \%$ of the total variance. The main cynicism predictors were organisational changes occurring over the previous year and reward (i.e. the fewer positive changes and rewards, the higher the cynicism observed); other significant predictors were perceived fairness, workload, control, skills development and work-group cohesion, with the model accounting for $26.5 \%$ of the total variance. The main efficacy predictor was control (i.e. the lower job control, the lower professional efficacy); other significant predictors were fairness, reward, and work-group cohesion, with the model accounting for approximately $16 \%$ of the total variance.

\section{The predictors of burnout}

Multivariate logistic regression analysis showed that some jobrelated characteristics maintained their significance with relation to burnout, even after the AWS, Evaluation of Changes and Management Areas scores had been entered into the model (Table 4). Specifically, the risk of burnout was significantly higher for staff involved in face-to-face interaction with patients and for those employed in mental health for more than 12 years. These two job-related factors represent the strongest predictors of burnout, with odds ratios respectively of 4.81 (95\% CI 1.70-13.57) and 3.24 (95\% CI 1.03-10.23). Yet, some perceived organisational factors also exerted a key role: low workload, high control, high reward, high fairness, positive changes and high work-group cohesion all showed evidence of being important protective factors against the risk of burnout.

\section{Discussion}

\section{Strengths and limitations}

To our knowledge, this is the first study examining burnout in a large, representative sample of mental health staff and different types of professional categories and contract conditions. It therefore represents a major research advance in the field, as mental health staff morale studies to date have mostly considered single groups of professionals. ${ }^{8,10,14,36,37}$ The present study's strengths lie in its: representativeness; sample size (approximately 2000 participants), the largest ever surveyed in research on burnout in mental health; and response rate (nearly $80 \%$ ), one of the highest ever reported in the literature. Moreover, this is the first study exploring predictors of burnout by considering not only individual sociodemographic and occupational characteristics, but also perceived contextual factors, by assuming that work environment can fully account for what has previously been considered the individual syndrome of burnout. ${ }^{20}$ Lastly, as far as we know, this is the first study in mental health to adopt the OCS, ${ }^{17}$ a new methodology based on the most recent conceptual developments in burnout research.

The study also has some limitations. First, job-independent factors (such as personal factors, problems related to the overall socioeconomic environment, labour market pressures) might have contributed to the high workforce stress rates observed, although the sample size (all mental health staff working within the catchment area were approached) and the regression results suggest the improbability of the substantial impact of these factors. Second, other contextual 'objective' variables not considered in the analyses might have exerted a significant role in the prediction of burnout. Third, the cross-sectional nature of the survey did not allow for the determination of causal relationships. Fourth, the generalisability of our findings should be taken with caution, as the study was conducted in the specificity of the Italian national healthcare system. Finally, the study did not address positive attitudes towards work, such as job satisfaction.

\section{Burnout prevalence among mental health staff}

Our findings confirmed the first hypothesis, since nearly twothirds of respondents reported high levels of emotional exhaustion, and a quarter expressed high levels of negative, cynical attitudes and feelings about service users and perceived low professional efficacy. Moreover, nearly one in five staff suffered from severe burnout. The burnout prevalence among Italian mental health staff is a cause for concern, as this condition can further deplete public mental health services' already scarce human resources. ${ }^{29}$ The proportion of Italian mental health staff scoring above the MBI cut-off was similar to that found by Prosser et $a l^{8}$ in London (24\%), but somewhat lower than reported by other studies conducted in the UK. ${ }^{36,11}$

Our results also confirmed the second hypothesis, since burnout has a different impact on the various professional categories, with severe burnout shown to be more frequent among social workers and psychiatrists. This finding is consistent with the results of a survey conducted in England and Wales ${ }^{14}$ in which social workers were shown to be more emotionally exhausted and more depersonalised than other mental health staff. High stress and emotional exhaustion levels among social workers represent a concern and are likely to worsen the low recruitment rates and retention problems associated with social work in many Western countries. ${ }^{23}$ One possible explanation for the high rates of emotional exhaustion in social workers may lie in their specific mental health sector role and responsibilities: social workers significantly contribute to the work of community mental health teams, but are also a scarce and declining resource in many countries, including Italy. ${ }^{29}$ It is therefore possible that they operate under a heavy workload without feeling valued for the work they do.

Psychiatry consistently shows signs of being a 'high-burnout' profession. ${ }^{38}$ The burnout symptom of emotional exhaustion is common in this profession, especially among community care psychiatrists. ${ }^{8,22}$ In a study conducted in New Zealand, two-thirds of psychiatrists described moderately to severely high levels of emotional exhaustion. ${ }^{24}$ The proportion of psychiatrists suffering from severe burnout in our sample was similar to that found in the UK in a national survey. ${ }^{39}$ Psychiatrists have the most intense form of interpersonal contact with patients and deal with extremely distressed or disturbed individuals on a regular basis. Although psychiatrists work fewer hours on average than physicians or surgeons, they report more emotional exhaustion and more severe depression because of workload ${ }^{15}$ than either physicians or surgeons do. This difference may be as a result of the particular nature of psychiatrists' work or to psychiatrists' specific personality characteristics, which might make them particularly vulnerable to job stress. ${ }^{40}$

\section{Factors predicting exhaustion, cynicism and efficacy}

Multivariate regressions led us to confirm the third study hypothesis, as we found that perceived organisational factors were the only significant predictors for the three MBI-GS subscales. Moreover, a set of specific predictors accounted for each MBI-GS subscale, with no significant study site effect nor professional category effects. In terms of strength of association, a main predictor was detected for each MBI-GS component (Fig. 1): high workload was most predictive of exhaustion; poor rewards and few perceived positive changes in an organisation were most predictive of disengagement from work; and lack of participation in decision-making was most predictive of reduced professional efficacy. Overall, our multivariate data seem to fit the 'job demand resources model', which postulates that job demands and lacking job resources are specifically linked to 


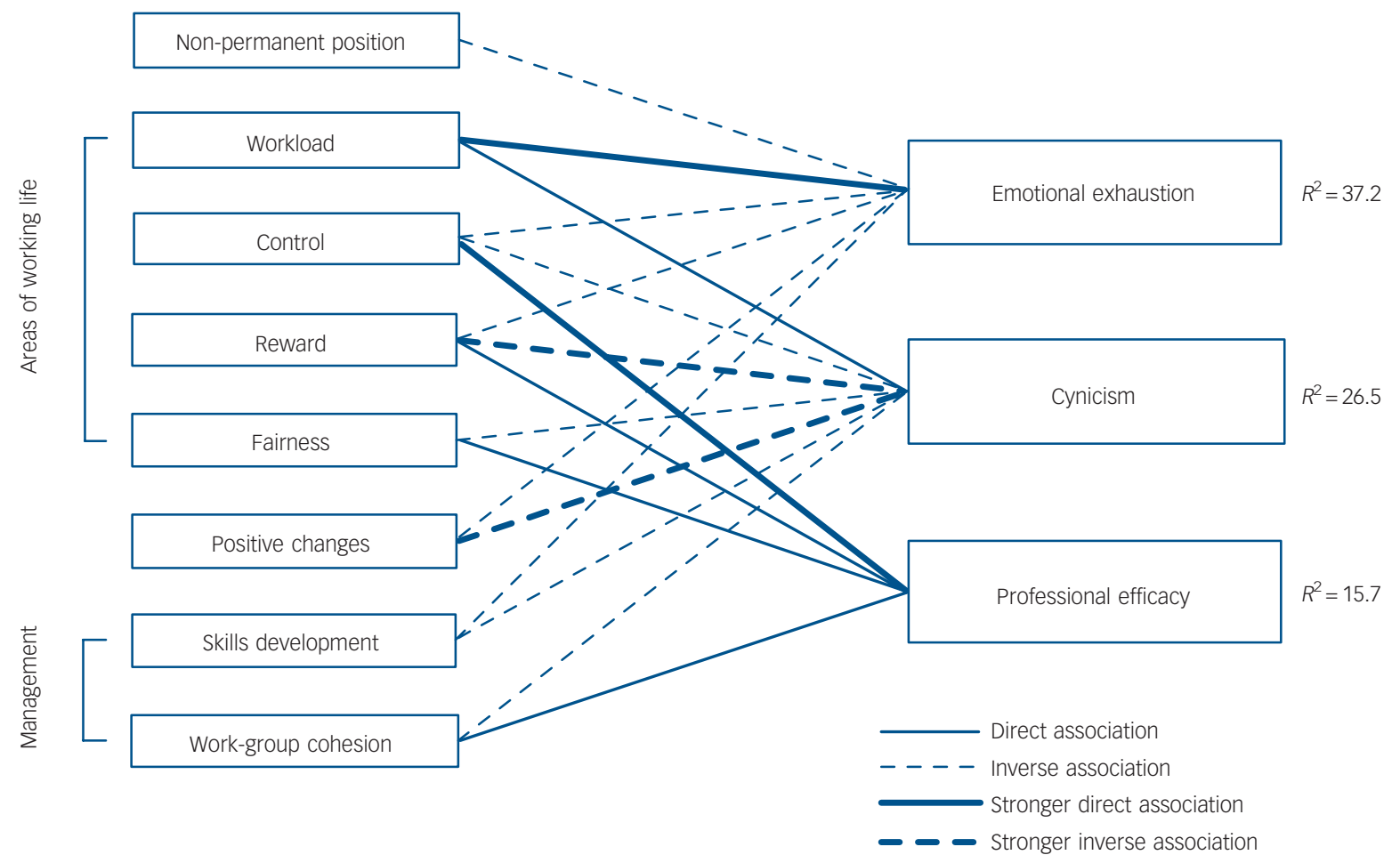

Fig. 1 Relation between significant predictors (individual and perceived contextual factors) and the three dimensions of burnout on the Maslach Burnout Inventory-General Survey.

emotional exhaustion and depersonalisation, respectively. ${ }^{41}$ The model assumes two underlying processes: that energy depletion is driven by high job demands (e.g. time pressure, emotional demands, cognitive demands, shift work) and is associated with exhaustion; and that erosion of motivation is driven by lack of job resources (e.g. supervisor support, feedback, control, task variety, financial rewards) and is associated with disengagement (cynicism) and lack of efficacy.

\section{Factors predicting burnout}

With respect to the predictors of burnout, our third hypothesis (i.e. that perceived occupational factors play a major role in predicting burnout) was only partially confirmed, as some individual characteristics were also found to be involved. Specifically, staff having close face-to-face interaction with patients and with longer job tenure in mental health were more likely to develop burnout. The observation that burnout levels are higher among healthcare workers who deal intensively with patients on a daily basis represents a consistent finding. ${ }^{20}$ However, studies assessing both negative and positive attitude towards work (such as, respectively, burnout and job satisfaction), found that exposure to patients is a major stressor, but also a key source of reward: ${ }^{10-12}$ staff can be emotionally burdened and at the same time experience high intrinsic job satisfaction because of the meaning they attach to their work. This apparent paradoxical finding indicates that the use of only negatively framed measures, such as the MBI, gives a partial view when assessing organisational well-being in healthcare contexts and that positive outcomes, such job satisfaction, should also be included.

The finding that a longer career is associated with higher burnout is controversial. Our results are consistent with those of other studies conducted in high-risk medical specialties. ${ }^{42,43}$ This finding seems logically plausible, since if burnout is the result of chronic job-related stress, older workers or staff with longer job tenure would be expected to have higher burnout levels. Yet, this finding contrasts with other studies, which found that older mental health staff tend to show lower levels of burnout than younger workers. ${ }^{9,24,44,45}$ Moore \& Cooper have formulated several hypotheses to explain this finding, including differences in position, control, money, influence and expertise. ${ }^{46}$ Prosser $e t$ al suggest that burnout can be offset by the benefits of experience and adaptation at both an individual and organisational level. ${ }^{12}$ However, it may also be possible that this represents a cohort effect reflecting the early departure from clinical work by those staff members who eventually succumb to burnout. ${ }^{44,23}$ Only the widespread adoption of repeated-measures studies in burnout research may lead to a better understanding of this aspect. ${ }^{23,47}$

Among perceived organisational factors, one management process (work-group cohesion) and two working life areas (fairness and control) best predicted burnout. We found that a poorly cohesive work group is at higher risk of burnout. Workgroup cohesion may be defined as the degree to which an individual believes that the members of his/her work group are willing to work together and are committed to the completion of the tasks and goals of the group. ${ }^{48}$ Group cohesion relates directly to job satisfaction, namely through human relations with fellow employees and supervisors. ${ }^{49,50}$ Therefore, work-group cohesion appears to be an important factor for mitigating stress-related effects on job performance and, in turn, for preventing burnout. It is interesting to note that team cohesion is increased by effective group performance; ${ }^{51}$ however, how to promote effective team working is a cause for concern, since only a minority of health staff employed in the British National Health Service report to be working in coherent and effective work teams. $^{52}$

Fairness is the second main burnout predictor. This administrative leadership dimension ${ }^{17}$ shares some qualities with 
reward and group cohesion. Fairness is a supervisor or management quality, in the sense that people of higher authority in a given organisation have the responsibility for making judgements and decisions that affect the work environment of staff members. Early research in this field suggested that staff members' perception of supervisors as being both fair and supportive contributes to acceptance of major organisational changes and reduces their susceptibility to burnout. ${ }^{53}$ The impact on performance, attitudes to work and well-being at work of an 'engaging' style of leadership (i.e. a leader who encourages and enables the development of an organisation characterised by a culture based on integrity, openness, transparency and concern for employees) has recently been documented. ${ }^{54}$ Therefore, this specific area of working life deserves further consideration in future research on mental health staff.

\section{Implications for practice}

Developing a favourable team climate should be considered a target in interventions designed to reduce staff burnout. Various strategies have been proposed to treat and to prevent burnout: ${ }^{55}$ most focus on individual solutions, such as removing a burntout worker from the job, or individual strategies to either strengthen the worker's internal resources or to change his/her work behaviour. Yet, these approaches are only partially effective, because most research, and our data are consistent with this view, has found that situational and organisational factors play a greater role in burnout than individual factors. Individually oriented approaches (e.g. coping skills or deep relaxation techniques) can help professionals alleviate their sense of exhaustion, but they do not deal with the other two components of burnout. Moreover, individual strategies are relatively ineffective in the workplace, where people have much less control over stressors than in other domains of their lives. This empirical recognition of six areas of working life therefore expands the range of options for organisational intervention. Rather than having intervention examine the work overload area, it might more effectively focus on other types of individual-work environment mismatch: for example, people may be able to tolerate greater workload if they value their work and feel they are doing something important or if they feel wellrewarded for their efforts. Intervention in this instance could therefore be aimed at the areas of reward and fairness.

Although the potential value of organisational intervention is great, these programmes are not easy to implement; ${ }^{56}$ they frequently require a complex degree of collaboration and considerable economic investment. Further research in the area of mental health is needed to identify those problematic aspects that might lend themselves to targeted forms of intervention.

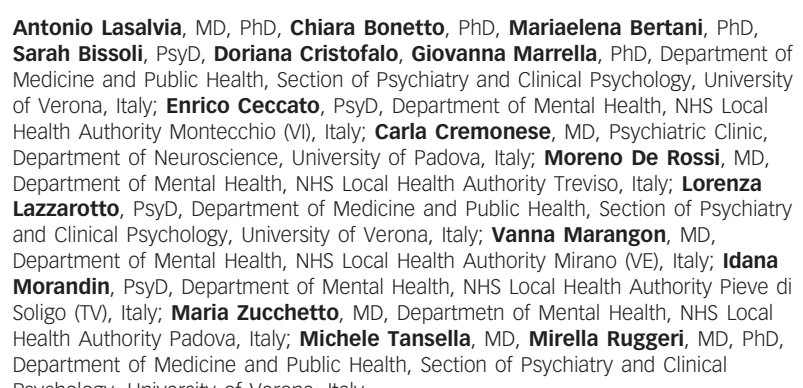

First received 23 Oct 2008, final revision 22 Jun 2009, accepted 13 Jul 2009

\section{Funding}

This study was supported by the Ricerca Sanitaria Finalizzata n. 219/05, Giunta Regionale del Veneto with a grant to A.L.

\section{Acknowledgements}

See the online supplement for details of members of the PICOS-Veneto group. We thank Professor Michael Leiter and Professor Graham Thornicroft for their helpful comments on an early version of this manuscript.

\section{References}

1 Maslach C. Burnout: The cost of Caring. Prentice-Hall, 1982.

2 Thomsen S, Soares J, Nolan P, Dallender J, Arnetz B. Feelings of professional fulfillment and exhaustion in mental health personnel: the importance of organisational and individual factors. Psychother Psychosom 1999; 68: 157-64.

3 Snibbe JR, Radcliffe T, Weisberger C, Richards M, Kelly J. Burnout among primary care physicians and mental health professionals in a managed health care setting. Psychol Rep 1989; 65: 775-80.

4 Priebe S, Fakhoury W, White I, Watts J, Bebbington P, Billings J, et al. Characteristics of teams, staff and patients: associations with outcomes of patients in assertive outreach. Br J Psychiatry 2004; 185: 306-11.

5 Sainsbury Centre for Mental Health. Finding and Keeping: Review of Recruitment and Retention in the Mental Health Workforce. The Sainsbury Centre, 2001

6 de Girolamo G, Bassi M, Neri G, Ruggeri M, Santone G, Picardi A. The current state of mental health care in Italy: problems, perspectives, and lessons to learn. Eur Arch Psychiatry Clin Neurosci 2007; 257: 83-91.

7 Maslach C, Leiter MP. The Truth about Burnout. Jossey-Bass, 1997.

8 Prosser D, Johnson S, Kuipers E, Szmukler G, Bebbington P, Thornicroft G. Mental health, "burnout" and job satisfaction among hospital and community-based mental health staff. Br J Psychiatry 1996; 169: 334-7.

9 Guthrie E, Tattan T, Williams E, Black D, Bacliocotti H. Sources of stress, psychological distress and burnout in psychiatrists: comparison of junior doctors, senior registrars and consultants. Psychiatr Bull 1999; 23: 207-12.

10 Edwards D, Burnard P, Coyle D, Fothergill A, Hannigan B. Stress and burnout in community mental health nursing: a review of the literature. J Psychiatr Ment Health Nurs 2000; 7: 7-14.

11 Reid Y, Johnson S, Morant N, Kuipers E, Szmukler G, Thornicroft G, et al. Explanations for stress and satisfaction in mental health professionals: a qualitative study. Soc Psychiatry Psychiatr Epidemiol 1999; 34: 301-8.

12 Prosser D, Johnson S, Kuipers E, Dunn G, Szmukler G, Reid Y, et al. Mental health, "burnout" and job satisfaction in a longitudinal study of mental health staff. Soc Psychiatry Psychiatr Epidemiol 1999; 34: 295-300.

13 Kilfedder CJ, Power KG, Wells TJ. Burnout in psychiatric nursing. J Adv Nurs 2001; 34: 383-96.

14 Evans S, Huxley P, Gately C, Webber M, Mears A, Pajak S, et al. Mental health, burnout and job satisfaction among mental health social workers in England and Wales. Br J Psychiatry 2006; 188: 75-80.

15 Deary IJ, Agius RM, Sadler A. Personality and stress in consultant psychiatrists. Int J Soc Psychiatry 1996; 42: 112-23.

16 Iacovides A, Fountoulakis K, Moysidou C, Lerodiakonou C. Burnout in nursing staff: a clinical syndrome rather than a psychological reaction? Gen Hosp Psychiatry 1997; 19: 419-28.

17 Leiter MP, Maslach C. Preventing Burnout and Building Engagement: A Complete Program for Organizational Renewal. Jossey-Bass, 2000.

18 Leiter MP, Maslach C. Areas of worklife: a structured approach to organizational predictors of job burnout. In Research in Occupational Stress and Well Being, Vol. 3: Emotional and Physiological Processes and Positive Intervention Strategies (eds Perrewe PL, Ganster DC): 91-134. JAI Press/ Elsevier, 2004

19 Maslach C, Goldberg J. Prevention of burnout: new perspectives. Appl Prev Psychol 1998; 7: 63-74.

20 Maslach C, Schaufeli WB, Leiter MP. Job Burnout. Annu Rev Psychol 2001; 52: 397-422.

21 Maslach C, Leiter MP. Early predictors of job burnout and engagement. J Appl Psychol 2008; 93: 498-512.

22 Korkeila JA, Töyry S, Kumpulainen K, Toivola JM, Räsänen K, Kalimo R. Burnout and self-perceived health among Finnish psychiatrists and child psychiatrists: a national survey. Scand J Public Health 2003; 31: 85-91. 
23 Lloyd C, King R. A survey of burnout among Australian mental health occupational therapists and social workers. Soc Psychiatry Psychiatr Epidemiol 2004; 39: 752-57.

24 Kumar S, Fischer J, Robinson E, Hatcher S, Bhagat RN. Burnout and job satisfaction in New Zealand psychiatrists: a national study. Int J Soc Psychiatry 2007; 53: 306-16.

25 Sørgaard KW, Ryan P, Hill R, Dawson I, OSCAR Group. Sources of stress and burnout in acute psychiatric care: inpatient vs. community staff. SOC Psychiatry Psychiatr Epidemiol 2007; 42: 794-802.

26 Eklund M, Hansson L. Relationships between characteristics of the ward atmosphere and treatment outcome in a psychiatric day-care unit based on occupational therapy. Acta Psychiatr Scand 1997; 95: 329-35.

27 Nash L, Gorrell J, Cornish A, Rosen A, Miller V, Tennant C. Clinical outcome of an early psychosis intervention program: evaluation in a real-world context. Aust N Z J Psychiatry 2004; 38: 694-701.

28 Rossberg Jl, Melle I, Opjordsmoen S, Friis S. Patient satisfaction and treatment environment: a 20 -year follow-up study from an acute psychiatric ward. Nord J Psychiatry 2006; 60: 176-80.

29 Lasalvia A, Gentile B, Ruggeri M, Marcolin A, Nosè F, Cappellari L, et al. Heterogeneity of the Departments of Mental Health in the Veneto Region ten years after the National Plan 1994-96 for Mental Health. Which implication for clinical practice? Findings from the PICOS Project. Epidemiol Psichiatr SoC 2007; 16: 59-70.

30 Leiter MP, Maslach C. Organizational Checkup Survey. Jossey-Bass, 2000.

31 Borgogni L, Galati D, Petitta L, Centro Formazione Schweitzer. II questionario di Checkup Organizzativo. Manuale dell'adattamento italiano [Organisational Checkup Survey. Manual of the Italian Adaptation]. O.S. Organizzazioni Speciali, 2005

32 Schaufeli WB, Leiter MP, Maslach C, Jackson SE. Maslach Burnout InventoryGeneral Survey. In The Maslach Burnout Inventory (3rd edn) (eds C Maslach SE Jackson, MP Leiter). Consulting Psychologists Press, 1996.

33 Maslach C, Jackson SE, Leiter MP. The Maslach Burnout Inventory (3rd edn) Consulting Psychologists Press, 1996.

34 Schaufeli WB, Van Dierendonck D. UBOS Utrecht Burnout Scale: Manual (in Dutch). Swets Test Publishers, 2000.

35 Rabe-Hesketh S, Skrondal A, Pickles A. GLLAMM Manual. University of California Berkeley, Division of Biostatistics, 2004 (http://www.bepress.com/ ucbbiostat/paper160/).

36 Onyett S, Pillinger T, Muijen M. Job satisfaction and burnout among members of community mental health teams. J Mental Health 1997; 6: 55-66.

37 Priebe S, Fakhoury W, Hoffmann K, Powell RA. Morale and job perception of community mental health professionals in Berlin and London. Soc Psychiatry Psychiatr Epidemiol 2005; 40: 223-32.

38 Kumar S. Burnout in psychiatrists. World Psychiatry 2007; 6: 186-9.

39 Pajak S, Mears A, Kendall T, Katona C, Medina J. Workload and Working Patterns in Consultant Psychiatrists. An Investigation into Occupational Pressure and Burdens. College Research Unit, Royal College of Psychiatrists, 2003.
40 Fischer J, Kumar S, Hatcher S. What makes psychiatry such a stressful profession? A qualitative study. Australas Psychiatry 2007; 15: 417-21.

41 Bakker AB, Demerouti E, Euwema MC. Job resources buffer the impact of job demands on burnout. J Occup Health Psychol 2005; 10: 170-80.

42 Quattrin R, Zanini A, Nascig E, Annunziata M, Calligaris L, Brusaferro S. Level of burnout among nurses working in oncology in an Italian region. Oncol Nurs Forum 2006; 33: 815-20.

43 Klersy C, Callegari A, Martinelli V, Vizzardi V, Navino C, Malberti F, et al. Burnout in health care providers of dialysis service in Northern Italy a multicentre study. Nephrol Dial Transplant 2007; 22: 2283-90.

44 Billings J, Johnson $\mathrm{S}$, Bebbington $\mathrm{P}$, Greaves $\mathrm{A}$, Priebe $\mathrm{S}$, Muijen $\mathrm{M}$, et al. Assertive outreach teams in London: staff experiences and perceptions. Pan-London Assertive Outreach Study, Part 2. Br J Psychiatry 2003; 183 139-47.

45 Reininghaus $U$, Priebe S. Assessing morale in community mental health professionals: a pooled analysis of data from four European countries. Soc Psychiatry Psychiatr Epidemiol 2007; 42: 237-43.

46 Moore K, Cooper C. Stress in mental health professionals: a theoretical overview. Int J Soc Psychiatry 1996; 42: 82-9.

47 Eichler T, Schützwohl M, Priebe S, Wright D, Adamowski T, Rymaszewska J, et al. Loss to follow-up in longitudinal psychiatric research. Epidemiol Psichiatr Soc 2008; 17: 138-47.

48 Riordan C, Weatherly E. Defining and measuring employees' identification with their work groups. Educ Psychol Meas 1999; 59: 310-24.

49 Gilbert JA, Tang LP. An examination of organizational trust antecedents. Public Pers Manage 1998; 27: 321-5.

50 Blegen MA. Nurses' job satisfaction: a meta-analysis of related variables. Nurs Res 1993; 42: 36-41.

51 Mullen $B$, Copper $C$. The relation between group cohesiveness and performance: an integration. Psychol Bull 1994; 115: 210-27.

52 Healthcare Commission. National NHS Staff Survey 2007: Summary of Key Findings. Commission for Healthcare Audit and Inspection, 2008 (http:// www.cqc.org.uk/_db/_documents/National_NHS_staff_survey_2007_ summary_of_key_findings_200804183620.pdf).

53 Leiter MP, Harvie P. Conditions of staff acceptance of organizational change: burnout as a mediating construct. Anxiety Stress Coping 1998; 11: 1-25.

54 Alimo-Metcalfe B, Alban-Metcalfe J, Bradley M, Mariathasan J, Samele C. The impact of engaging leadership on performance, attitudes to work and wellbeing at work: A longitudinal study. J Health Organ Manag 2008; 22 : 586-98.

55 Marine A, Ruotsalainen J, Serra C, Verbeek JH. Preventing occupational stress in healthcare workers. Cochrane Database of Systematic Reviews 2006, issue 4.

56 Killaspy $\mathrm{H}$, Johnson S, King M, Bebbington P. Developing mental health services in response to research evidence. Epidemiol Psichiatr Soc 2008; 17 47-56. 